Letrônica, Porto Alegre, v. 7, n. 1, p. 225-249, jan./jun., 2014

\title{
A PROFICIÊNCIA DE REVISORES DE TEXTOS PROFISSIONAIS EM UMA TAREFA DE DETECÇÃO DE ERROS
}

\section{THE PROFICIENCY OF PROFESSIONAL REVISERS IN AN ERROR DETECTION TASK}

\author{
Délia Ribeiro Leite* \\ José Olímpio de Magalhães**
}

\begin{abstract}
Resumo: 0 revisor de textos profissional tem a função de corrigir e aprimorar o texto de outrem, de forma a contribuir para a qualidade da publicação. A revisão sob uma perspectiva cognitiva constituiu o embasamento teórico principal deste trabalho. Nessa perspectiva, a revisão tem sido abordada como um subprocesso da escrita, sendo que revisores e produtores de textos experientes seriam capazes de detectar com mais frequência erros de níveis globais cujas demandas ao processamento são maiores. Visando analisar a proficiência em revisão de textos, foi elaborada uma tarefa de leitura e detecção de erros, realizada por 14 revisores e 14 não revisores, na qual os sujeitos deveriam ler e revisar pequenos textos jornalísticos projetados no computador, clicando com o mouse nos erros e/ou inadequações que encontrassem. Verificou-se que a proficiência está ligada à capacidade de detectar tipos específicos de erros.
\end{abstract}

Palavras-chave: Revisão de textos; Proficiência; Detecção de erros.

\begin{abstract}
Professional proofreaders are responsible for correcting and improving text with the aim of improving the quality of written publications. The present paper addresses revision from a cognitive theoretical framework. From this perspective, editing has been approached as a sub-process of writing; more experienced text editors and proofreaders are better able to detect mistakes at more global levels; these mistakes, in turn, demand more processing. With the goal of investigating proofreading proficiency, a reading and error detection task is proposed. The task was performed by 14 proofreaders and by 14 nonprofessional proofreaders. The task consisted of reading and editing short journalistic texts, which were displayed on a computer. Proofreading was carried out by clicking the mouse on the mistakes and/or inadequacies found. The results show that proofreading proficiency is associated with the ability to detect specific error types.
\end{abstract}

Keywords: Revision; Proficiency; Error detection.

\footnotetext{
${ }^{*}$ Doutora em Linguística pela Universidade Federal de Minas Gerais. Revisora de textos do Conselho Regional de Contabilidade de Minas Gerais.

${ }^{*}$ Doutor em Linguística. Professor titular do Departamento de Letras da Universidade Federal de Minas Gerais.
} 


\section{Introdução}

A revisão está diretamente relacionada com o processo de leitura e produção de textos. Por isso, ao relermos um texto que produzimos, buscamos assumir uma visão exotópica $^{1}$ e verificar aspectos diversos da estrutura textual, de forma a identificar possíveis erros ${ }^{2}$, bem como trechos cuja interpretação seja difícil ao leitor para o qual aquele texto é destinado. Trilhamos esse processo quando relemos um bilhete, um email informal, um trabalho acadêmico ou um livro a ser publicado.

$\mathrm{Na}$ escola, aliás, o processo de releitura é incentivado pelos professores. Nos Parâmetros Curriculares Nacionais, a revisão de textos é o primeiro item do tópico "Análise e reflexão sobre a língua" e é um aspecto importante da formação dos alunos, a ser abordado pelo professor: "a revisão do texto assume um papel fundamental na prática de produção." (BRASIL, 1997, p. 51).

Essa perspectiva vê a revisão como uma ferramenta para se identificarem inadequações, a fim de buscar a qualidade do texto que está sendo produzido. Nesse sentido, a revisão pode ser realizada pelo próprio autor do texto, caracterizando-se como uma "autorrevisão".

Além da autorrevisão, há também a revisão feita pelo profissional revisor de textos, cuja ocupação é a leitura dos textos produzidos por outrem, de forma a identificar inadequações de linguagem e propor correções ou alterações diversas. Isso porque nem sempre o autor é o melhor leitor para revisar o seu próprio texto, seja por questões técnicas, relativas aos seus conhecimentos, inclusive no campo dos estudos da linguagem, seja por questões práticas: a exotopia pode ficar comprometida, tendo em vista que o texto, ao ser lido pelo próprio autor, perde a imprevisibilidade, o que pode fazer com que inadequações de linguagem de ordem diversa não sejam percebidas.

Durante a revisão de um texto, o revisor está sujeito a falhas, até mesmo porque essa atividade é bastante minuciosa e exige alto grau de atenção e concentração. Pinto

\footnotetext{
${ }^{1}$ A visão exotópica é aquela em que a leitura é realizada com um olhar diferente daquele do produtor do texto, um olhar que simularia a leitura realizada pelo leitor para o qual aquele texto é destinado.

2 Neste trabalho, a expressão "erro" será utilizada para fazer referência às situações em que, na tarefa de revisão, era esperada a intervenção do revisor, inclusive em função de se tratar de textos jornalísticos que exigiam adequação à norma-padrão e à coerência. Os "erros", portanto, correspondem à não correspondência do texto com a norma-padrão ou à incidência de problemas de coerência que afetam a compreensão do texto. Com o uso dessa expressão, não se pretende desconsiderar toda a discussão e o avanço da Linguística no sentido de descrever a língua em suas mais diversas variantes, sem dominância de nenhuma. A expressão "erro", portanto, é utilizada com propósitos específicos.
} 
(1993) expõe duas categorias de "erros" em revisão: os de composição e os do próprio revisor. Ribeiro (2007) elenca os erros de composição:

\begin{abstract}
saltos são omissões de letras, palavras ou frases, por exemplo; piolhos são sinais ou letras duplicados, ou ainda qualquer pequeno erro tipográfico; pastéis são inversões indevidas; gatos são trocas indevidas; e gralhas são caracteres que sobram no texto (RIBEIRO, 2007, p. 7).
\end{abstract}

Já os erros do revisor abarcam as falhas relativas ao desconhecimento da língua. Para Ribeiro (2007, p. 8), os erros do revisor são tratados "como 'cochilo', o que torna a tarefa de revisar algo para se fazer atenta e detalhadamente". Nesse sentido, são muitos os fatores que podem estar envolvidos e trazer como consequência o erro.

Neste trabalho, de cunho quantitativo, pretendeu-se investigar a proficiência na detecção de erros, por meio da comparação entre o desempenho de revisores profissionais e de não profissionais em uma tarefa de leitura e detecção de erros. Desta forma, esta pesquisa visou verificar se o revisor de textos é um profissional especializado e identificar as qualidades do revisor. Além disso, espera-se compreender melhor as falhas do revisor, que podem estar ligadas a aspectos como o tipo de erro ou a experiência em revisão de textos.

Visando atingir os objetivos propostos, foi elaborada uma tarefa de leitura e detecção de erros, na qual os sujeitos deveriam ler e revisar pequenos textos jornalísticos projetados no computador ${ }^{3}$, clicando com o mouse nos erros e/ou inadequações que encontrassem. Foi registrada a palavra sobre a qual eles clicavam e o momento em que isso ocorria.

Neste artigo, primeiramente será levantado o embasamento teórico sobre revisão de textos, com um enfoque especial às pesquisas de caráter cognitivo que investigam a expertise em revisão, após serem citados estudos sobre a aquisição e o desenvolvimento do desempenho experto. Em seguida, serão expostos os procedimentos metodológicos que nortearam a aplicação do experimento, bem como os métodos estatísticos escolhidos para a análise dos dados. Após terem sido apresentados os resultados obtidos, serão discutidas as contribuições para a área, assim como as possíveis implicações da pesquisa ora realizada.

\footnotetext{
${ }^{3}$ Na seção "Metodologia", serão detalhados os procedimentos dessa tarefa de revisão, assim como os textos utilizados e o controle realizado na composição dos estímulos.
} 


\section{Proficiência em revisão de textos}

Espera-se que o revisor de textos proficiente seja capaz de detectar e corrigir o maior número possível de erros, bem como consiga identificar inadequações e, se for o caso, propor melhorias no texto revisado. Não há, no entanto, uma definição clara quanto ao caminho a ser seguido para o desenvolvimento dessa competência. Para o experiente editor Martins Filho (2007), por exemplo, o profissional precisa ter uma boa formação na área de língua portuguesa, mas se destaca pela experiência. 0 editor cita, inclusive, um bom revisor cuja formação foi somente empírica (MARTINS FILHO, 2007). Assim, a experiência tem sido vista como essencial para o desenvolvimento da expertise, não só no que se refere à atividade de revisão de textos, mas em diversas outras atividades e profissões. Chi (2006b, p. 167), por exemplo, considera que "Expertise, por definição, refere-se à manifestação de habilidades e da compreensão resultantes do acúmulo de grande quantidade de conhecimento" (tradução nossa) ${ }^{4}$.

Um problema enfrentado pelos pesquisadores que investigam a expertise decorre da própria identificação de um expert. De acordo com Ericsson (2006, p. 686), vários estudos têm evidenciado que aqueles nomeados como experts por seus pares muitas vezes não apresentam uma performance excepcional. Da mesma forma, há casos em que a expertise parece diminuir com a experiência (ERICSSON; PRIETULA; COKELY, 2007, p. 2).

Em decorrência disso, há dois segmentos de estudos sobre expertise. Um deles está interessado, principalmente, nas diferenças intersujeitos e, assim, compara sujeitos com e sem experiência ou formação, de forma a, ao verificar as diferenças, inferir as competências intrínsecas à proficiência em uma determinada atividade. Essa primeira vertente investiga a expertise sob uma perspectiva relativa. Em contraposição, outros estudos visam descrever e explicar as características de sujeitos que, dentre aqueles que exercem uma atividade, destacam-se como os melhores. Eles têm, portanto, o foco em uma investigação "absoluta", e não relativa (cf. CHI, 2006a, p. 21), e buscam as diferenças intrasujeito, ou seja, a evolução de um sujeito no desenvolvimento da competência e da expertise.

\footnotetext{
4 "Expertise, by definition, refers to the manifestation of skills and understanding resulting from the accumulation of a large body of knowledge" (CHI, 2006b, p. 167).
} 
A segunda vertente de estudos seleciona os sujeitos considerados experts verificando o destaque dentre os demais da mesma área. Isso é facilmente identificável, por exemplo, na área esportiva, em que os campeões são vistos como aqueles que detêm o nível máximo de conhecimento e técnica. Nessa perspectiva, tem sido evidenciado que a prática deliberada é essencial para o desenvolvimento de uma performance experta, bem como que, para se tornar um expert, é necessário um tempo mínimo de experiência de dez anos, na maioria das atividades (ERICSSON, 2006; ERICSSON; PRIETULA; COKELY, 2007).

Por outro lado, os estudos que lançam mão de uma abordagem relativa podem simplesmente caracterizar os grupos investigados como expertos versus não expertos ou, ainda, utilizar uma escala que vai desde os inexperientes até os expertos (KLEIN; HOFFMAN, 1992; CHI, 2006a).

0 expert não precisa ter uma performance consistente em todos os níveis, mas sim na atividade que lhe é familiar e na qual é especializado. Nessa atividade, os experts têm uma representação mais profunda e geral, enquanto os novatos têm um sistema de representação mais superficial (CHI, 2006b).

Klein e Hoffman (1992, p. 209) consideram que os experts veem coisas que outras pessoas não podem ver, devido à sua habilidade de ver padrões, distinções e antecedentes e consequências. Por isso, os experts podem identificar regularidades e padrões e detectar quando há violações, prevendo, inclusive, consequências e alterações futuras, o que demonstra uma visão mais dinâmica da atividade.

Hayes et al. (1987) também consideram que revisores experientes são mais proficientes do que os novatos, pois, em uma tarefa de revisão, revisores novatos persistiram em não detectar erros que foram facilmente encontrados pelos experientes. Nessa tarefa, os novatos leram por várias vezes a mesma sentença que continha uma inadequação, sem conseguir identificá-la. Tanto que, das 327 vezes em que novatos as sentenças, somente em $26 \%$ das vezes conseguiram identificar o erro. Ao final da tarefa, os revisores novatos identificaram somente $36 \%$ deles, ao passo que os experientes identificaram 58\%. Da mesma forma, os experientes diagnosticaram $43 \%$ das inadequações, e os novatos diagnosticaram 15\%.

Esses autores compararam revisores experientes e novatos e, assim, corroboram os estudos cujo enfoque é a expertise relativa. Foram comparados dois grupos: dos 14 
sujeitos, sete eram graduandos (dois deles classificados pelos professores como bons produtores de textos e os demais, como inexperientes); três eram editores de textos profissionais; e quatro eram experientes instrutores de escrita, que também tinham experiência como editores. De acordo com os autores, os revisores experientes diferem dos novatos quanto à definição da tarefa de revisão, principalmente porque os experientes têm um maior conhecimento sobre como fazer planos a serem seguidos na execução da tarefa, além de criarem antecipadamente um inventário de "problemas" a serem identificados e incluírem objetivos globais de revisão que levam em conta a situação de comunicação. Assim, os revisores experientes apresentaram uma tabela de meios e fins mais bem elaborada e, por isso, detectaram mais tipos de problemas, utilizando mais procedimentos para resolvê-los do que os novatos. Além disso, os autores verificaram que os revisores experientes frequentemente leem o texto primeiramente para captar sua ideia principal, sem proceder a correções de erros de superfície, que são realizadas em uma segunda leitura. Essa estratégia, porém, não é muito adotada pelos novatos.

Vigneau et al. (1997) compararam revisores experientes (professores de língua materna - no caso, francês) e revisores inexperientes (alunos do ensino secundário) e verificaram que, embora os primeiros tenham realizado mais correções do que os segundos, essa diferença não se refere ao nível dos erros corrigidos, pois, em ambos os casos, os erros de superfície foram mais corrigidos do que os de níveis mais altos. $\mathrm{Na}$ verdade, os revisores experientes adéquam melhor as correções aos problemas, inclusive no que se refere às operações utilizadas para cada um desses níveis.

Tanto Vigneau et al. (1997) quanto Hayes et al. (1987) compararam revisores experientes e inexperientes e, assim, investigaram a expertise em revisão de textos sob uma perspectiva relativa. Outros autores, porém, investigam a proficiência em revisão de textos comparando sujeitos de diferentes faixas etárias ou mesmo crianças e adultos. Nesse caso, as diferenças encontradas podem ultrapassar o campo da experiência e adentrar outros fatores, como o amadurecimento de estratégias e do próprio sistema cognitivo.

Plumb et al. (1994), por exemplo, compararam universitários e estudantes colegiais e verificaram que a idade é um fator que influencia a quantidade de correções realizadas em textos com erros, sendo que os mais velhos corrigiram mais erros do que 
os mais novos. Já Hinckel (1991) comparou dois grupos que considerava diferir na proficiência em escrita: o primeiro, mais avançado, foi composto por crianças de dez anos e oito meses; e o segundo foi composto por crianças de oito anos e nove meses. Elas deveriam realizar a detecção e correção de erros de níveis diversos, em uma ou mais leitura do texto. $\mathrm{O}$ autor verificou diferenças somente no número de detecções, já que as crianças de nível mais avançado detectaram mais erros. Não houve diferença na quantidade de correções, mas o grupo mais experiente demandou mais tempo para realizar as correções.

Roussey, Piolat e Guercin (1990) também compararam crianças e adultos durante uma atividade de revisão de textos narrativos e descritivos, visando verificar quais estratégias são utilizadas, dentre as seguintes possíveis: estratégia simultânea, em que o sujeito realiza correções de erros de diversos níveis em uma primeira leitura; estratégia "local-global", na qual o sujeito corrige em uma primeira leitura erros de níveis mais locais e superficiais e, em uma segunda leitura, erros de níveis mais globais; e estratégia "global-local", o oposto da anterior. Os autores verificam que os adultos utilizam estratégias diferentes em função do tipo de texto: estratégia simultânea nos narrativos e "local-global” nos descritivos. Já as crianças diferem dos adultos porque, nos textos narrativos, utilizam a estratégia "local-global”, mas nos descritivos não é possível identificar a estratégia utilizada, pois elas alternam o padrão ao longo da tarefa, sem, muitas vezes, conseguirem melhorar o texto. Da mesma forma, Dedeyan, Largy e Negro (2006) também consideram que os adultos utilizam métodos mais automáticos de detecção do que as crianças, já que estas aplicam uma espécie de algoritmo de detecção de erros de superfície, que pressupõe recursividade ao invés de automatismo.

As conclusões desses estudos comparativos têm mostrado não só diferenças de desempenho, sendo que, em todos os casos, os mais experientes são mais proficientes, mas também nos níveis de processamento dos tipos de erros e nas estratégias utilizadas na detecção e correção. Os mais experientes, em geral, têm um conhecimento mais aprofundado das variáveis da revisão, tanto na definição da tarefa quanto no que se refere à influência dos tipos de erros e textos. Por isso, conseguem escolher estratégias diferenciadas em função dessas variáveis, demonstrando uma visão mais completa da atividade de revisão, que explica a maior proficiência deles seja na detecção, seja na correção dos erros. Portanto, esses estudos corroboram as teorias sobre revisão com 
abordagem cognitiva, que buscam explicar os processos envolvidos na revisão e os sistemas cognitivos utilizados.

\section{Metodologia}

\subsection{Sujeitos}

Os sujeitos participantes da pesquisa foram divididos em dois grupos: não profissionais e profissionais, sendo que cada grupo foi composto por 14 sujeitos.

No grupo dos não profissionais, participaram da pesquisa estudantes de ensino superior que não cursavam Letras nem Comunicação Social. Optou-se por essa restrição por se considerar que a formação nesses dois cursos é pré-requisito em diversos concursos públicos para a investidura de cargos de revisão e, com isso, esse estudante poderia ter uma formação mais aprofundada em estudos de linguagem, o que o diferencia de um grupo que representaria sujeitos não revisores. Nesse grupo, 7 sujeitos cursavam Psicologia; 4, Ciências Biológicas; 1, Geografia; 1, Fonoaudiologia; e 1, Antropologia. A idade variou de 18 a 39 anos e, dos participantes, 6 estavam no primeiro período do curso; 2, no segundo; 2, no terceiro período; 1 , no quinto; 1 , no sexto período; 1, no sétimo e 1, no décimo período do curso. Esses estudantes foram selecionados porque nunca trabalharam profissionalmente com revisão de textos, embora isso não signifique que eles nunca tenham realizado uma revisão, inclusive autorrevisão.

Para a escolha dos profissionais, foi pré-requisito que o sujeito trabalhasse profissionalmente com revisão, fosse em órgãos públicos, na iniciativa privada ou como autônomo. A idade variou entre 23 e 62 anos. Todos os participantes tinham formação em Letras, sendo que um deles estava no último período do curso, mas já acumulava três anos de experiência ${ }^{5}$ em revisão de textos. Com relação ao tempo de experiência dos revisores, 5 deles trabalhavam com revisão no mínimo há um ano e no máximo há quatro anos; 5, no mínimo há cinco e no máximo há nove anos; e 4, por dez anos ou mais.

\footnotetext{
5 Para a inclusão desse sujeito em fase final de formação em Letras, foi verificado se sua performance na detecção de erros era discrepante do restante dos revisores, por meio de uma análise de clusters, e ele não tinha um comportamento discrepante.
} 


\subsection{Construção dos textos}

Os textos, do gênero jornalístico, redigidos especialmente para o experimento, consistiram de um parágrafo informativo (o lead 6 ). Em cada sessão experimental, totalizaram 50 textos a serem revisados, constantes do Anexo I deste artigo (8 sem erros, 22 com um erro, 7 com dois erros, 9 com três erros e 4 com quatro erros). Dessa forma, conforme demonstrado na Tab. 1, a seguir, em cada sessão experimental, havia 79 erros/inadequações a serem detectados.

Tabela 1 - Número de erros por texto

\begin{tabular}{l|l|l}
\hline Número de erros no texto & Número de textos & $\begin{array}{l}\text { Número de erros } \mathbf{X} \text { número de } \\
\text { textos }\end{array}$ \\
\hline 0 & 8 & 0 \\
\hline 1 & 22 & 22 \\
\hline 2 & 7 & 14 \\
\hline 3 & 9 & 27 \\
\hline 4 & 4 & 16 \\
\hline Total & 50 & 79 \\
\hline
\end{tabular}

Na tabela 2, a seguir, são enumerados os tipos de erros.

Tabela 2 - Tipos de erros nos textos

\begin{tabular}{l|l}
\multicolumn{1}{c|}{ Tipo de erro } & \multicolumn{1}{c}{ Quantidade de erros } \\
\hline Supressão de preposição & 10 \\
\hline Anáfora incorreta & 10 \\
\hline Acentuação & 11 \\
\hline Concordância & 22 \\
\hline Digitação & 6 \\
\hline Incoerência & 7 \\
\hline Ortografia & 13 \\
\hline Total & 79 \\
\hline
\end{tabular}

Visando uniformizar ainda mais os textos, foi controlado, ainda, o tema, sendo os 50 textos distribuídos entre os seguintes temas: Futebol, Cultura, Economia, Política,

\footnotetext{
${ }^{6}$ Nas matérias jornalísticas, o primeiro parágrafo, também chamado de "lead", deve "fornecer a maior parte das respostas às seis perguntas básicas: o que, quem, quando, onde, como e por quê.” (MARTINS, 1997, p. 17).

${ }^{7}$ Houve um erro de pontuação que foi agrupado junto aos de digitação para possibilitar a posterior análise dos dados.
} 
Policial, Cotidiano, Ciência e Turismo. Os textos apresentaram de duas a quatro sentenças, com, em média, 55 palavras.

\subsection{Aplicação do experimento}

Para a construção e aplicação do experimento, foi utilizado o rastreador ocular produzido pela SR Research, modelo EyeLink 1000, disponível no Laboratório de Psicolinguística da Universidade Federal de Minha Gerais ${ }^{8}$. A coleta dos dados foi realizada nesse Laboratório. Primeiramente, os sujeitos eram informados de que se tratava de uma pesquisa sobre revisão de textos. Após assinarem o Termo de Consentimento ${ }^{9}$, era iniciada a tarefa.

Foi solicitado que os participantes lessem o texto procurando identificar erros e, ao identificarem um erro, deveriam clicar com o mouse sobre ele. Constou nas instruções que os textos foram construídos especificamente para a pesquisa e, assim, os fatos narrados não precisavam necessariamente ser verdadeiros.

Os textos eram apresentados em uma tela de computador, aleatorizados. Primeiramente, eram apresentadas as instruções, o equipamento era calibrado e os participantes realizavam um pequeno treino de leitura e detecção de erros em três pequenos textos. Nesse treino, havia um texto sem erros, um com dois erros e um com quatro erros, sendo que os erros acrescentados eram tanto de níveis superficiais quanto de níveis globais, para que, na prática do treino, os sujeitos delimitassem a tarefa de revisão da maneira mais ampla possível, sem ser necessário que o aplicador apresentasse uma definição de revisão de textos. Por isso, caso algum participante pedisse informações mais detalhadas sobre a atividade de revisão, o experimentador se restringia a informar que era para o sujeito se comportar como se estivesse fazendo a revisão do texto, com a detecção de erros.

\footnotetext{
8 Os resultados apresentados neste artigo são uma subparte da tese de doutorado intitulada "O olhar do profissional: estudo do movimento ocular na leitura realizada por revisores de textos" (Délia Ribeiro Leite), orientada por José Olímpio de Magalhães. Por esse motivo, o equipamento utilizado foi um rastreador ocular que, embora possa ser utilizado em experimentos off-line, foi utilizado em sua função on-line, tendo sido registrados, portanto, além do local e momento de detecção dos erros, também os movimentos dos olhos dos sujeitos durante a realização da tarefa.

${ }^{9}$ Projeto aprovado pelo COEP (Comitê de Ética em Pesquisa) da Universidade Federal de Minas Gerais, Parecer no 262.765/2013.
} 
Depois do treino, eles deveriam realizar a leitura e a revisão de cada texto, detectando os erros. Para passar para o próximo texto, deveriam clicar sobre o teclado. A revisão de cada texto deveria ser realizada em, no máximo, $60.000 \mathrm{~ms}$, pois, caso se ultrapassasse esse limite de tempo, o programa passava automaticamente para uma tela em branco. Esse tempo foi definido com base no projeto piloto realizado durante a pesquisa.

A cor de fundo era branca, a letra preta e de tamanho 20, com espaçamento 3,5. Foi retirado o máximo possível do brilho da tela do computador, para evitar fadiga visual.

Como os participantes deveriam realizar a identificação dos erros, não lhes foi solicitado que realizassem um teste de interpretação ao final de cada texto. Comumente, essas questões são acrescentadas às tarefas em estudos da área de Psicolinguística, para garantir que os sujeitos estejam atentos àquilo que leem. No entanto, como eles teriam de realizar a revisão dos textos, essa atenção já seria garantida, desde que a tarefa fosse corretamente cumprida.

\subsection{Análise estatística}

Primeiramente, os dados foram tabulados e explorados descritivamente, verificando-se medidas de tendência central como média, mediana e desvio padrão (a depender do tipo de variável e da distribuição), bem como com a visualização por meio de gráficos como boxplot, gráfico de barras, gráfico de densidade e de médias, também escolhidos conforme o tipo de variável investigada.

Foi, então, realizada a estatística inferencial, escolhendo-se o teste estatístico mais adequado em função dos dados analisados. 0 nível de significância adotado foi de $95 \%$, portanto, $\alpha$ foi definido como 0,05 . 0 programa utilizado para a análise estatística foi o $\mathrm{R}^{10}$.

No experimento realizado nesta pesquisa, foram coletadas amostras repetidas dos sujeitos, ou seja, cada sujeito leu 50 textos, sendo que a revisão de cada texto deveria ser realizada em, no máximo, 60.000ms. Dessa forma, deve-se considerar que houve um delineamento do tipo longitudinal, em que são analisadas as características dos mesmos

\footnotetext{
${ }^{10}$ Disponível em http://www.r-project.org/. Acesso em 2 de março de 2013.
} 
elementos amostrais (indivíduos) ao longo de um período de tempo, mesmo que esse período tenha sido curto (uma sessão experimental de cerca de 45 minutos). Portanto, pode haver diferenças de comportamento entre os sujeitos ao longo da tarefa, bem como de comportamento de um mesmo sujeito ao longo da tarefa. Isso foi levado em consideração na análise inferencial, com a escolha do modelo de regressão misto como o teste mais adequado. Os modelos mistos são assim denominados porque investigam tanto os efeitos fixos quanto os aleatórios.

As variáveis aleatórias são aquelas relacionadas a efeitos na variância da resposta que a princípio não são de interesse do pesquisador. Em uma replicação do experimento, não são repetíveis, pois foram escolhidas aleatoriamente de uma população. Nesta pesquisa, foram variáveis aleatórias os sujeitos participantes e os textos experimentais. Essas variáveis podem gerar efeitos sobre os dados, ou seja, pode ocorrer um padrão de comportamento específico de um sujeito ou em um determinado texto.

Já as variáveis fixas são aquelas que podem ser controladas e que representam o tratamento, sendo repetíveis. Nesta pesquisa, as variáveis fixas foram os graus de expertise em revisão, os tipos de erros e o número de erros em cada texto. No modelo de regressão misto ${ }^{11}$ ainda é possível verificar a relevância da interação entre esses fatores, assim como a evolução dos sujeitos ao longo da tarefa. 0 objetivo de se analisar a evolução da detecção de erros ao longo da tarefa é verificar se houve efeito de familiaridade com a tarefa, ou mesmo de fatiga ao longo da realização do experimento, tendo em vista que foram coletadas medidas repetidas. Assim, é possível analisar o comportamento de cada sujeito ou grupo na detecção de erros ao longo da realização do experimento. Para tanto, é acrescentado como variável fixa a sequência de estímulos (Trial).

A sequência de estímulos refere-se ao número de leituras de textos ao longo da tarefa. Os textos eram apresentados em uma ordem aleatória, porém, como se tratava de medidas repetidas, cada sujeito realizava a leitura de 50 textos. Assim, para cada sujeito, havia 50 estímulos apresentados em sequência. Não se deve confundir isso com um código de cada texto. Como os textos eram apresentados de forma aleatória, aquele que,

\footnotetext{
${ }^{11}$ Para informações sobre o cálculo realizado na composição de um modelo de regressão misto, sugerimos a consulta de Baayen (2008), tendo em vista que a explicação detalhada desse teste estatístico foge ao escopo deste artigo.
} 
na sequência, corresponde a 1, para cada sujeito, não é necessariamente o mesmo texto, mas equivale à primeira vez em que cada sujeito leu um texto durante a tarefa.

Quanto à detecção dos erros, trata-se de uma variável binária, isto é, uma variável que só pode assumir um dos dois possíveis valores: detectou X não detectou. Nesse caso, dentre os modelos de regressão, o mais adequado é o generalizado para dados de distribuição binomial (BAAYEN, 2008).

Portanto, o modelo de regressão linear misto é adequado como método estatístico neste trabalho porque permite comparar os grupos e condições experimentais.

\section{Resultados}

Em cada sessão experimental, havia 79 erros a serem detectados, sendo: 10 de supressão de preposição; 10 de anáfora incorreta; 11 de acentuação; 22 de concordância; 6 de digitação; 7 de incoerência; e 13 de ortografia. As detecções de erros compõem uma amostra de dados binomiais, em que são possíveis duas possibilidades: detectou versus não detectou. Portanto, os dados foram analisados por meio de um modelo de regressão linear generalizado misto para distribuições binomiais ${ }^{12}$.

O modelo mais adequado apresentou como variáveis aleatórias os sujeitos e os textos. Já como variáveis fixas, foram escolhidos: sequência dos estímulos (trial) ${ }^{13}$; número de erros existentes no texto (erro); grupos de expertise (exper) e tipo de erro (tipo), assim como a interação entre essas três últimas variáveis.

Os grupos de expertise corresponderam a: expertise 0 , nenhuma experiência em revisão (não revisores); expertise 1, experiência de 1 a 4 anos; expertise 2, experiência de 5 a 9 anos; e expertise 3, experiência acima de 10 anos. Já quanto ao número de erros, os textos variavam entre 0 e 4 erros, como indicado na Tabela 1 deste artigo.

Os resultados são apresentados na Tab. 3, a seguir:

\footnotetext{
${ }^{12}$ Para detalhes mais aprofundados da construção de modelos de regressão mistos nesta pesquisa, indicamos Leite (2014).

${ }^{13}$ Essa expressão foi explicada anteriormente, na seção 3.4, sobre a análise estatística. 
Tabela 3 - Modelo de regressão generalizado misto para dados binomiais com a detecção de erros como variável dependente; sujeitos e textos como variáveis aleatórias e trial, número de erros no texto, graus de expertise $(0,1,2$ e 3$)$ e tipo de erros como variáveis fixas

\begin{tabular}{|c|c|c|c|}
\hline Variáveis aleatórias & Variância & $\begin{array}{l}\text { Desvio } \\
\text { padrão }\end{array}$ & \\
\hline Texto & 0,384 & 0,6197 & \\
\hline Sujeito & 0,275 & 0,5244 & \\
\hline Variáveis fixas & Subdivisão & z valor & p valor \\
\hline Trial & & 1,979 & 0,04780 \\
\hline Tipo de erro & Anáfora & $-1,871$ & 0,06128 \\
\hline Tipo de erro & Digitação & $-2,962$ & 0,00305 \\
\hline Tipo de erro & Ortografia & -2.825 & 0,00473 \\
\hline Número de erros * Expertise & Expertise 3 & 1,982 & 0,04745 \\
\hline Número de erros * Tipo de erro & Ortografia & 2,443 & 0,01457 \\
\hline Expertise $*$ Tipo de erro & Expertise $1 *$ Incoerência & $-2,101$ & 0,03568 \\
\hline Expertise * Tipo de erro & Expertise $3 *$ Ortografia & 2,398 & 0,01648 \\
\hline $\begin{array}{l}\text { Número de erros } * \text { Expertise }{ }^{*} \\
\text { Tipo de erro }\end{array}$ & Expertise $3 *$ Digitação & $-1,738$ & 0,08216 \\
\hline $\begin{array}{l}\text { Número de erros * Expertise } * \\
\text { Tipo de erro }\end{array}$ & Expertise $1 *$ Incoerência & 1,828 & 0,06750 \\
\hline $\begin{array}{l}\text { Número de erros } * \text { Expertise } * \\
\text { Tipo de erro }\end{array}$ & Expertise $2 *$ Ortografia & $-1,701$ & 0,08887 \\
\hline $\begin{array}{l}\text { Número de erros }{ }^{*} \text { Expertise }{ }^{*} \\
\text { Tipo de erro }\end{array}$ & Expertise $3 *$ Ortografia & $-2,610$ & 0,00907 \\
\hline
\end{tabular}

Foram variáveis estatisticamente significativas os erros de digitação e de ortografia. Já quanto ao trial e aos erros de anáfora incorreta, houve diferença marginalmente significativa. Os erros de ortografia e digitação foram significativos porque os sujeitos, em geral, fizeram poucas detecções (z-valor negativo). 0 Gráfico 1 indica a média de detecções referente a cada tipo de erro ${ }^{14}$.

Gráfico 1: Gráfico de efeitos da variável independente tipo de erro - variável dependente detecção do erro tipo effect plot

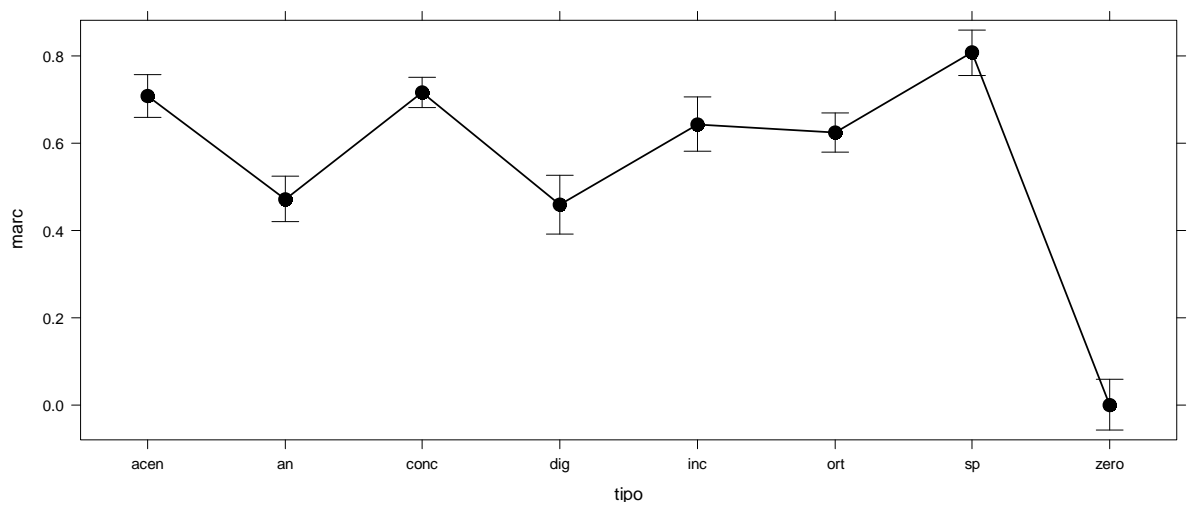
14 "Zero" corresponde aos textos em que não havia erros a serem detectados e, nesse caso, obviamente, a
média de detecções foi 0. 
Em alguns casos, a interação entre as variáveis foi significativa. Isso ocorreu quanto à interação entre o número de erros no texto e os erros de digitação, bem como entre o número de erros no texto e os erros de ortografia. Em ambos os casos, houve um aumento do número de detecções à medida que se aumentava o número de erros por texto. Isso pode ser visualizado no Gráfico 2.

Gráfico 2: Gráfico de barras - detecções dos erros - interação entre tipo de erros e número de erros no texto

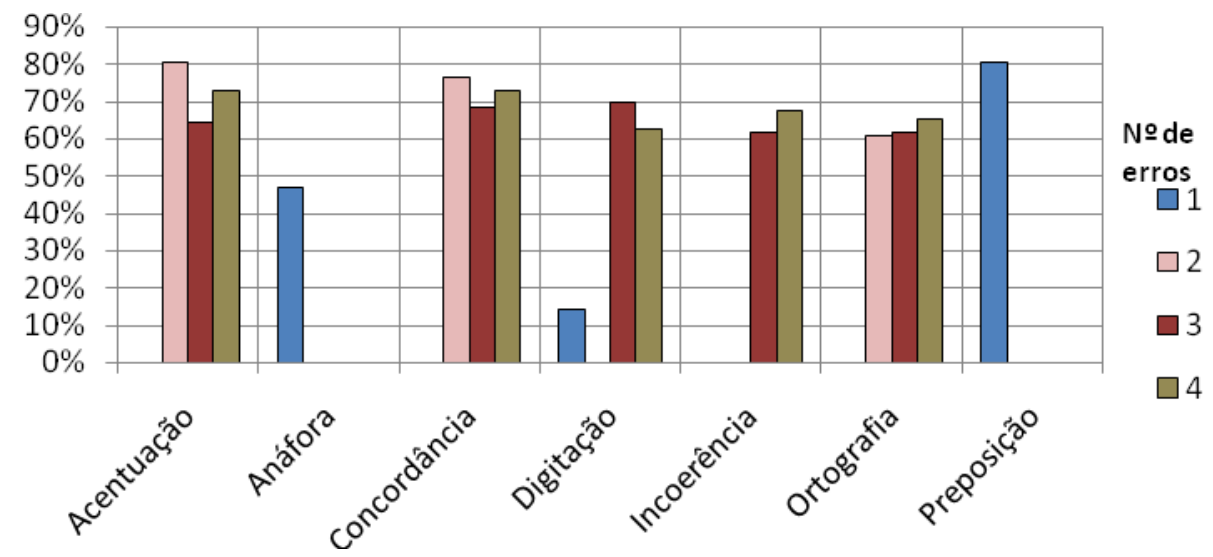

Foram significativas, também, as interações entre os grupos de expertise e os erros de incoerência e ortografia. Quando o tipo de erro foi incoerência, foi significativa a interação com o grupo de expertise 1. Já quando o tipo de erro foi ortografia, a interação significativa foi com o grupo de expertise 3.

Gráfico 3: Gráfico de barras - detecção de erros - interação entre tipo de erro e graus de expertise

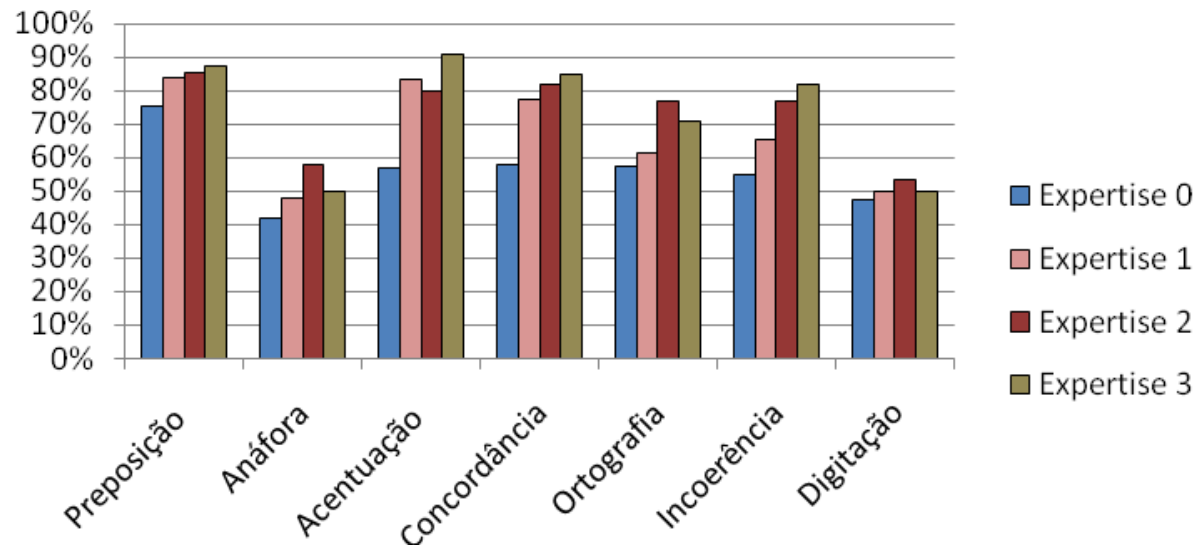


Ainda foi marginalmente significativa ${ }^{15}$ a interação entre o número de erros no texto e o grupo de expertise 3. No Gráfico 4, é possível visualizar que, nesse grupo, houve um aumento significativo de detecções de erros entre os textos em que havia 1 e 2 erros, sendo que, naqueles em que havia 2, 3 ou 4 erros, o número de detecções manteve-se praticamente estável.

Gráfico 4: Gráfico de barras - detecções dos erros - interação entre número de erros no texto e graus de expertise

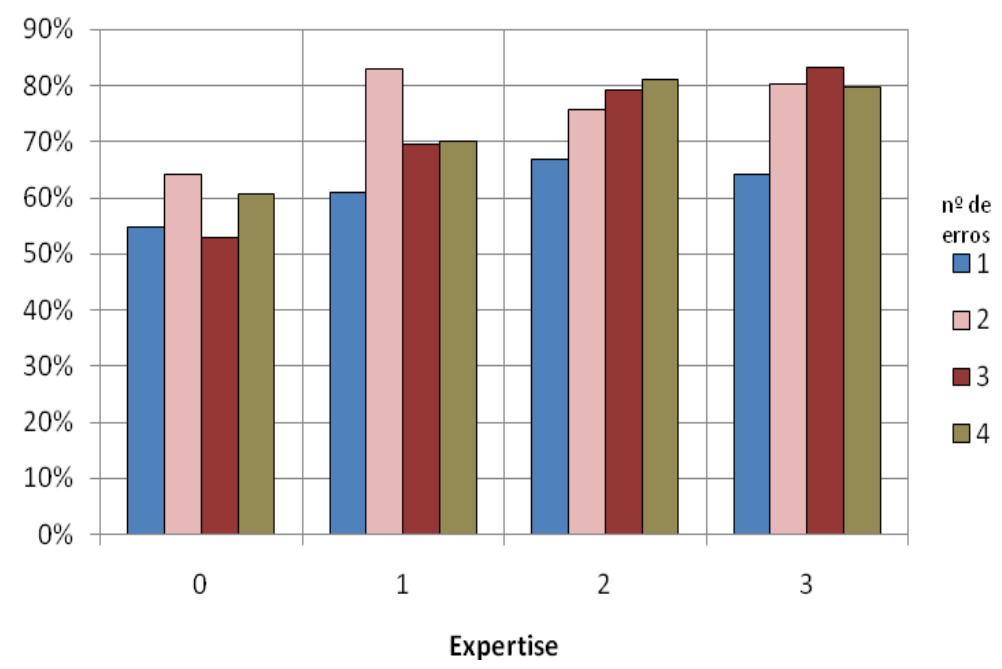

Também foi marginalmente significativa a interação entre o número de erros nos textos, o grupo de expertise 3 e os erros de digitação, sendo que a probabilidade de detecção de erros, nesse caso, foi menor (z-valor negativo). Da mesma forma, foi marginalmente significativa a interação entre o número de erros, o grupo de expertise 1 e os erros de incoerência, mas a probabilidade de detecção aumentou (z-valor positivo). Já quanto à interação entre o número de erros, o grupo de expertise 2 e os erros de ortografia, houve diferença marginalmente significativa, com uma probabilidade de detecção menor (z-valor negativo).

Por fim, foi uma variável estatisticamente significativa a interação entre o número de erros, o grupo de expertise 3 e os erros de ortografia. No entanto, os resultados referentes à interação entre o número de erros, os níveis de expertise e os

\footnotetext{
${ }^{15}$ Em estatística, a expressão "marginalmente significativo" faz referência a um p-valor menor do que 0,1 e maior ou igual a 0,05. Já "significativo" refere-se a um p-valor menor do que 0,05 e maior ou igual a 0,01; "muito significativo", a um p-valor menor do que 0,01 e maior ou igual a 0,001 e "altamente significativo" a um p-valor menor do que 0,001 .
} 
tipos de erros devem ser levados em consideração com cautela, tendo em vista que as amostras foram bastante reduzidas.

O modelo generalizado misto mostrou-se adequado, pois o C índex de concordância foi 0,834 e o coeficiente de correlação de Somers Dxy entre os valores esperados e os reais foi 0,668 , o que valida o modelo.

Os grupos de expertise, portanto, não foram uma variável significativa em um modelo que vise prever a detecção de erros. Esses grupos somente se mostraram significativos quando foi analisada a interação com o número de erros existentes no texto, bem como com o tipo de erro.

Nesse aspecto, os revisores que compunham o grupo de expertise 3, com mais experiência, apresentaram uma porcentagem de detecções de erros bastante constante nos textos em que havia dois, três e quatro erros, sendo que as detecções foram menores naqueles em que havia somente um erro a ser detectado. Esse grupo também teve um desempenho diferenciado na detecção dos erros de ortografia, o que foi estatisticamente significativa, sendo que a probabilidade de detecção desse tipo de erro foi maior nesse grupo do que nos demais. No entanto, quando foi analisada a interação entre número de erros no texto, o grupo de expertise 3 e os erros de ortografia, a probabilidade de detecção desse tipo de erro foi diminuindo à medida que havia mais erros a serem detectados no texto.

Esse resultado é particularmente interessante ao se considerar que os erros de ortografia foram um preditor significativo no modelo, apresentando um z-valor negativo, o que significa que, em geral, a probabilidade de detecção desse tipo de erro foi menor do que de outros. 0 mesmo ocorreu quanto aos erros de digitação. Além disso, a detecção desses dois tipos de erros, em geral, aumentou à medida que se aumentava o número de erros a serem detectados no texto. 0 grupo de expertise 3, portanto, apresentou um padrão oposto ao geral, pois sua probabilidade de detecção desse tipo de erro, como um todo, foi maior, mas diminuiu à medida que se aumentava o número de erros a serem detectados no texto. Além disso, o grupo de expertise 3 também diminuiu a detecção dos erros de digitação à medida que se aumentava o número de erros a serem detectados no texto, o que também foi um padrão oposto ao geral.

0 grupo de expertise 2, por sua vez, apresentou uma tendência a assumir o mesmo comportamento do de expertise 3 quanto à detecção dos erros de ortografia: 
diminuir o número de detecções à medida que se aumentava o número de erros a serem detectados nos textos, o oposto do padrão geral.

Já o grupo de expertise 1 apresentou um comportamento diferenciado quanto à detecção dos erros de incoerência, pois a probabilidade de detecção desse tipo de erro foi menor nesse grupo. No entanto, ela foi aumentando à medida que havia mais erros a serem detectados nos textos.

Portanto, a análise inferencial indica que, apesar de não haver uma diferença estatisticamente significativa entre os grupos de expertise quando se analisa a detecção de erros como um todo, essa diferença surge em tipos de erros específicos, em especial naqueles que foram preditores significativos no modelo de regressão. Nesse caso, os revisores com mais experiência mostraram um padrão diferenciado quando à detecção desses erros significativos, em especial dos de ortografia, pois tiveram um desempenho mais proficiente, detectando mais erros, além de um padrão diferente dos demais quando se analisa a interação com o número de erros a serem detectados no texto. Os resultados, portanto, demonstram que a proficiência não está ligada às detecções como um todo, mas sim a detecções de tipos de erros específicos, especialmente daqueles em que há uma dificuldade geral de identificação.

\section{Conclusão}

Neste trabalho, foi analisada a proficiência na detecção de erros de revisores profissionais e de sujeitos que não trabalham profissionalmente com revisão. Foram encontradas diferenças significativas na interação entre os graus de expertise dos participantes e os tipos de erros. Havia 4 graus de expertise: 0, que correspondia aos casos em que os sujeitos não tinham experiência em revisão profissional (não profissionais); 1, em que a experiência era de até 4 anos; 2, experiência de 5 a 10 anos; e 3, mais de 10 anos de experiência. Embora, ao se analisar a detecção de erros como um todo, os graus de expertise não tenham sido significativos, eles foram relevantes em tipos de erros específicos, em especial os de digitação e ortografia. Assim, os resultados indicaram que a proficiência está ligada à capacidade de detectar tipos específicos de erros que os demais sujeitos têm dificuldade de detectar. 
Esses resultados vão contra as considerações de John Hayes et al. (1987), segundo os quais os revisores experientes detectam mais erros do que os inexperientes, padrão que se manifestaria de uma maneira geral. Ao mesmo tempo, os resultados caminham no sentido do proposto por François Vigneau et al. (1997), que compararam revisores experientes e inexperientes e verificaram que, embora os primeiros tenham realizado mais correções do que os segundos, essa diferença não se refere ao nível dos erros corrigidos, pois, em ambos os casos, os erros de superfície foram mais corrigidos do que os de níveis mais altos. Na verdade, os revisores experientes adéquam melhor as correções aos problemas, inclusive no que se refere às operações utilizadas para cada um desses níveis.

Por fim, deve-se considerar que esta pesquisa investigou especificamente a detecção de erros, que é uma das etapas da revisão, sendo que, além dela, é necessário também realizar as correções, etapa esta que não foi investigada neste momento, mas que merece consideração em estudos posteriores da área, inclusive naqueles em que se verifique a qualidade das correções realizadas, de cunho, portanto, qualitativo. Tendo em vista que os estudos sobre a revisão de textos profissional são escassos, principalmente com abordagem cognitiva, essa pesquisa teve um caráter exploratório e trouxe considerações iniciais importantes não só para o estudo da performance de revisores profissionais, mas também para o estudo do processo de revisão de textos.

\section{Referências}

BAAYEN, R. Harald. Analyzing Linguistic Data: A Practical Introduction to Statistics using R. Cambridge: Cambridge University Press, 2008.

BRASIL. Secretaria de Educação Fundamental. Parâmetros Curriculares Nacionais: língua portuguesa. Brasília: 1997.

CHI, Michelene T. H. Two Approaches to the Study of Experts' Characteristics. In: ERICSON, K. et al. Anders. The Cambridge Handbook of Expertise and Expert Performance. New York: Cambridge University Press, 2006a, p. 21-29.

. Laboratory Methods for Assessing Experts' and Novice' Knowledge. In: ERICSON, K. et al. Anders. The Cambridge Handbook of Expertise and Expert Performance. New York: Cambridge University Press, 2006b, p. 167-183.

DEDEYAN, Alexandra; LARGY, Pierre; NEGRO, Isabelle. Mémoire de travail et détection d'erreurs d'accord verbal: étude chez le novice et l'expert. Langages, 164, 2006, p. 57-70. 
ERICSSON, K. Anders; PRIETULA, M. J.; COKELY, Edward T. The making of an expert. Harvard Business Review, July-August 2007, p. 1-7.

HAYES, J. R. et al. Cognitive processes in revision. In S. ROSENBERG (Ed.), Advances in psycholinguistics: (Vol. II.) Reading, writing, and language processing. Cambridge: Cambridge University Press, 1987, p. 176-240.

HINCKEL, V. Competences de revision au C.E.2 et C.M.2 selon le type d'erreurs et le nombre de lectures. Repères, n. 4, 1991, p. 139-152.

KLEIN, Gary A.; HOFFMAN, Robert R. Seeing the invisible: perceptual-cognitive aspects of expertise. In: RABINOWITZ, M. (ed.). Cognitive Science Foundations of Instruction. Mahwah, N. J: Eribaum, 1992, p. 203-226.

LEITE, Délia Ribeiro. $O$ olhar do profissional: estudo do movimento ocular na leitura realizada por revisores de textos. Tese de doutorado. Faculdade de Letras, UFMG, 2014.

MARTINS, Eduardo. Manual de Redação e Estilo: O Estado de São Paulo. São Paulo: Moderna, 1997.

PINTO, Ildete Oliveira. O livro: Manual de preparação e revisão. São Paulo: Ática, 1993.

PLUMB, Carolyn et al. Error correction in text: testing the processing-deficit and knowledge-deficit hypotheses. Reading and writing: a interdisciplinary jornal, n. 6, 1994, p. 347-360.

RIBEIRO, Ana Elisa. Em busca do texto perfeito: (in)distinções entre as atividades do editor de texto e do revisor de provas na produção de livros. Juiz de Fora: XII Congresso Brasileiro de Ciências da Comunicação da Região Sudeste, 2007.

ROUSSEY, Jean-Yves; PIOLAT, Annie; GUERCIN, François. Revising strategies for different text types. Language and Education, v. 4, n. 1, 1990, p. 51-65.

VIGNEAU, François et al. La révision de texte: une comparaison entre réviseurs débutants et experimentes. Revue des sciences de l'éducation, v. 23, n. 2, 1997, p. 271-288.

Recebido em março de 2014.

Aceito em maio de 2014. 


\section{ANEXO I - Textos do experimento}

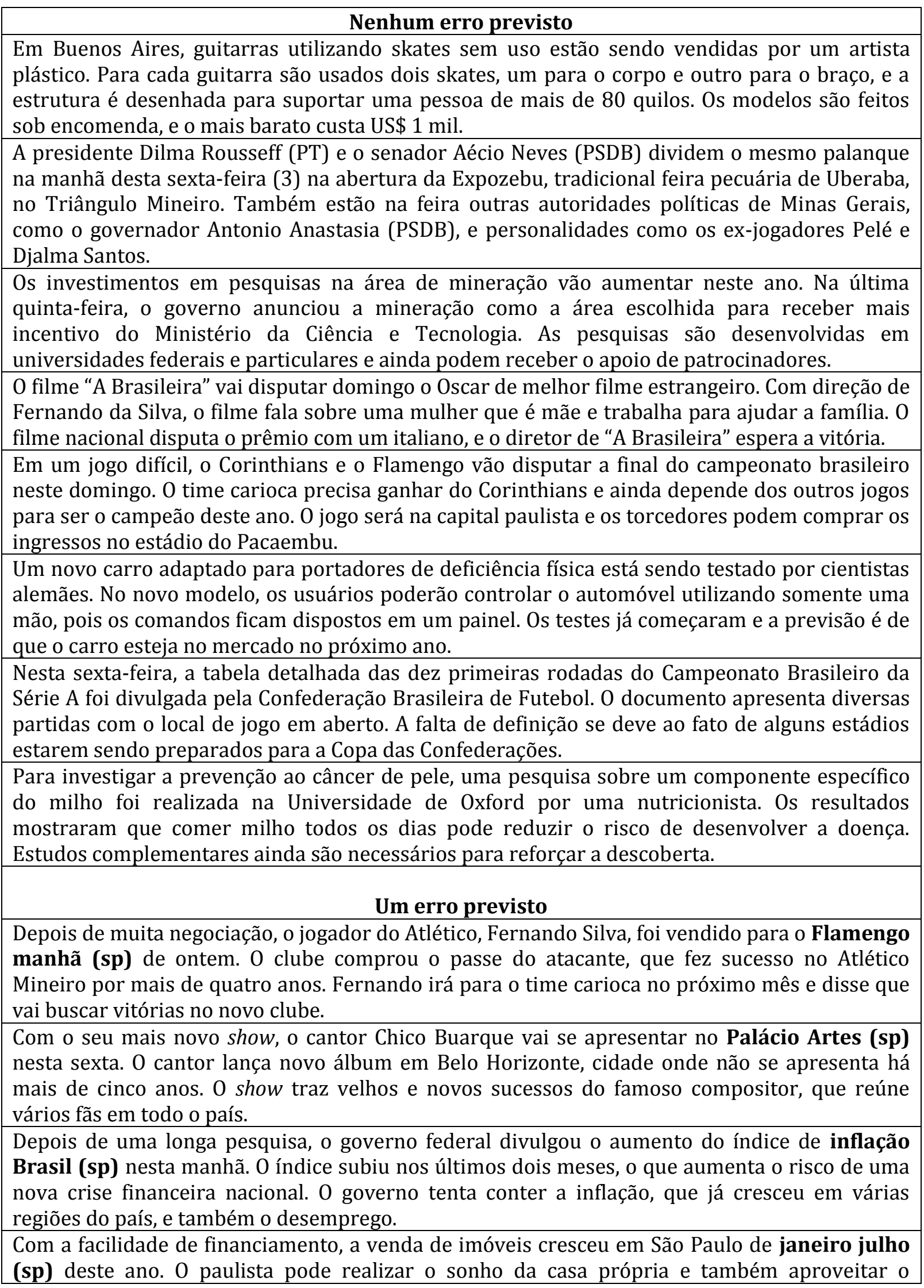


mercado de imóveis em alta. A expectativa é de que o setor tenha um crescimento maior com a queda dos juros dos bancos.

Deputado federal há dez anos, Carlos Leite anunciou a sua candidatura para o governo baiano tarde (sp) de ontem. Carlos se candidatou pelo Partido dos Trabalhadores e vai disputar com Luis da Veiga, candidato do Partido Verde. Carlos Leite já começou sua campanha e disse que vai trabalhar para fazer da Bahia um lugar melhor.

Após um longo período, o clássico entre Atlético Mineiro e Cruzeiro contará com a presença duas (sp) torcidas mineiras. 0 Cruzeiro será o mandante da partida e vai disponibilizar uma parte dos ingressos para a torcida adversária. 0 jogo do Campeonato Mineiro será na próxima semana, na inauguração do novo Mineirão, e terá policiamento reforçado.

Com a proximidade da Copa do Mundo, o governo mineiro está investindo em cursos gratuitos inglês (sp) para taxistas. Os cursos estão ocorrendo em vários bairros de Belo Horizonte e terão duração de um ano e meio. Os participantes vão aprender noções básicas de vocabulário e conversação para garantir a qualidade no atendimento aos estrangeiros.

Em um artigo, pesquisadores da Unesp anunciaram a descoberta de um novo medicamento de combate câncer (sp) de mama. Conforme publicado na revista Saúde Hoje, a pesquisa foi realizada com duzentas mulheres com câncer em fase inicial. A Unesp pretende iniciar a produção do medicamento no próximo ano, depois de conseguir a patente do produto.

Com o maior rigor da Lei Seca, as abordagens policiais aumentaram no Rio de Janeiro março (sp) deste ano. A Polícia Militar do Rio de Janeiro divulgou os dados referentes ao mês, e o aumento foi expressivo. A Polícia aumentou as abordagens porque considera que muitos dos acidentes têm relação com a embriaguez ao volante.

De acordo com pesquisadores da UFMG, o consumo de bebidas alcoólicas aumentou entre as mulheres classe (sp) média alta. A causa seria o aumento do estresse e a nova composição familiar, com casamentos cada vez mais tardios. Os pesquisadores alertam para o perigo do consumo excessivo de álcool, que pode acarretar dependência e várias doenças.

Antes do debate com os candidatos a prefeito, a atuação de Márcio Lacerda foi avaliada por uma escritora. A mulher estava na plateia e foi escolhida naquele momento pela Globo Minas para avaliar o atual prefeito. A secretária (an) destacou a criação de novas escolas e criticou a falta de políticas voltadas para a segurança.

Em audiência pública, o projeto de construção de três ciclovias em Belo Horizonte foi criticado por um motorista. 0 objetivo do vereador que apresentou o projeto é incentivar um estilo de vida mais saudável na cidade. 0 passageiro (an) destacou que as ciclovias podem prejudicar 0 trânsito e diminuir o número de vagas de estacionamento.

Na noite de ontem, um bebê foi encontrado próximo às margens da Lagoa da Pampulha por um argentino. $O$ bebê estava enrolado em uma manta, e a mãe da criança foi presa horas depois do ocorrido. $\mathrm{O}$ americano (an) confirmou em depoimento que a mãe abandonou a criança no local e fugiu logo em seguida.

Em um desfecho inesperado, a cena de um assassinato ocorrido em São Paulo foi registrada por um engenheiro. Com o fim do casamento, uma mulher foi baleada pelo ex-marido, perto do salão de beleza onde trabalhava. 0 arquiteto (an) estava fotografando sua filha no local, no exato momento em que o homem cometeu o crime.

Devido a várias ocorrências de dengue, um mosquito gigante foi colocado no Centro de Salvador por uma estudante. 0 objetivo é conscientizar a população e chamar a atenção para os cuidados com a prevenção da doença. A professora (an) criou o mosquito utilizando objetos descartados em locais impróprios, nos quais foi encontrado foco de dengue.

Em uma situação constrangedora, o escritor Rubem Alves foi criticado no lançamento do seu livro por um advogado. 0 fato ocorreu em São Paulo, numa das lojas da Leitura, no Shopping Morumbi, e gerou muitos comentários. 0 psicólogo (an) acusou o escritor de plágio e pretende fazer uma denúncia formal à Academia Brasileira de Letras.

Os acervos dos museus paulistas poderão ser apreciados gratuitamente aos sábados neste mês de maio. A programação, organizada pela Secretaria Estadual da (dig) Cultura, sob o tema 
"Museu Meu e Seu: De Todo Mundo", faz parte das atividades do Dia Internacional dos Museus, comemorado no próximo dia 18.

Na (dig) final do jogo entre Cruzeiro e Fluminense, uma pedra foi atirada no campo por uma torcedora. $\mathrm{O}$ objeto atingiu o jogador do Cruzeiro Rodrigo Pereira, que sofreu um corte na cabeça. 0 médico da equipe informou que o ferimento não foi grave e que o jogador já entrará em campo no próximo jogo do time.

Em uma famosa rede social, as alíquotas do Imposto de Renda estão sendo duramente questionadas por uma contadora. A mulher fez um levantamento dos últimos dez anos e verificou que a cobrança deveria ser bem menor. A jornalista (an) alega que os reajustes foram inferiores à inflação acumulada e já tem vários seguidores na internet.

Depois de sua última partida pelo Flamengo, o jogador Marco Henrique foi homenageado no Maracanã por um vereador. 0 jogador vestiu a camisa do clube por mais de dez anos e acaba de anunciar sua aposentadoria. O diplomata (an) representou a torcida na homenagem e entregou ao ídolo uma carta assinada por quinhentos mil torcedores.

Em uma nova série televisiva, o Caminho de Compostela vai ser percorrido durante dois meses por um cineasta. $O$ objetivo é mostrar as belezas do local, simulando uma viagem real, com uma abordagem próxima aos telespectadores. 0 fotógrafo (an) vai gravar suas aventuras e as melhores cenas serão exibidas pela Globo, a partir de março.

No Shopping Del Rey, uma pasta com trinta mil reais foi esquecida em uma loja por um deputado. Uma das vendedoras da loja encontrou a pasta e ligou para o número de celular anotado na etiqueta. 0 governador (an) ficou tão feliz em recuperar todo o dinheiro perdido que até pretende gratificar a honesta vendedora.

\section{Dois erros previstos}

Enquanto tentava defender seu pai de uma briga, Kerolly Alves (13) foi baleada ontem pelo dono de uma pizaria (ort). A discussão aconteceu em frente ao estabelecimento e foi gravado (conc) pelas câmeras de segurança do local. 0 estado da adolescente é grave.

Durante um debate sobre o assunto transmitido pela Rede TV, a meiaentrada (ort) para estudantes foi duramente criticada por um universitário. No entanto, o benefício foi defendido por um político que apresentou os resultados de uma pesquisa Datafolha realizada na capital paulista. De acordo com a pesquisa, a maioria da população paulistana (91\%) aprovam (conc) o benefício.

Nesta quarta-feira, uma carta contendo veneno foi enviada à presidente Dilma Roussef por um médica (conc). 0 veneno letal poderia ter causado a morte da presidente. A polícia já prendeu o autor do atentado, que declarou que tinha intençao (acen) ${ }^{16}$ de matar a presidente porque considera que seu governo não atende às reais necessidades do povo.

Os carros importados vão ficar mais caro (conc) a partir da próxima semana. Com o novo pacote do governo, o imposto sobre os carros importados aumentará em $0,5 \%$, e os juros também serão maiores para essa categoria. 0 ministro da economia disse que a medida é uma forma de extimular (ort) a produção nacional.

Os brasileiros já devem começar a programar as viajens (ort) de final de ano para não comprometer o orçamento, garantem os especialistas. Várias agencias (acen) de viagens oferecem pacotes com antecedência de quase um ano, o que diminui a incidência de juros, deixando o passeio mais barato. Os destinos preferidos ainda são Rio de Janeiro e Nordeste.

Um guia publicado pela Editora Escala dá dicas sobre os melhores planos de celular para cada tipo de viagem. 0 viajante pode escolher o melhor plano para o seu tipo de viagem e o pais (acen) de destino. 0 guia ainda aborda outras questão (conc) que mexem com o orçamento em viagens, como custo-benefício da hospedagem e melhor forma de deslocamento.

\footnotetext{
${ }^{16}$ Embora o til seja um diacrítico que sinaliza nasalização, e não necessariamente acentuação, esse erro foi agrupado aos demais acentuação porque, em "intenção", a última sílaba, "ção", é também aquele em que se encontra o acento lexical.
} 
A pre-venda (acen) de ingressos para o show de Paul McCartney no estádio Mineirão, em 4 de maio, começará às $10 \mathrm{~h}$ desta quinta feira (ort), dia 28 de março. As entradas custam entre $\mathrm{R} \$$ 80 (meia) e R\$ 600 (pista premium). Além de Minas Gerais, o ex-beatle passará por Goiânia e Fortaleza.

\section{Três erros previstos}

Um pacote de medidas para melhora (ort) a segurança foi anunciado ontem pelo prefeito de Belo Horizonte, Márcio Lacerda. Em votação pública, a segurança foi considerada o maior problema da cidade pelos moradores e serão prioridades (conc) do governo. 0 prefeito disse que vai investir em câmaras (ort) e aumentar o policiamento nos locais mais violentos.

Com a crise financeira, viagens com destino a (acen) Europa estão sendo cada vez mais procurada (conc) por brasileiros. Os brasileiros estão aproveitando o Euro em baixa e os incentivos dos países para o turismo. Os gastos podem ser $30 \%$ menor (conc) do que no mesmo período do ano passado, garantem os especialistas.

Segundo fonte próximas (conc) às negociações, o Bradesco desistiu de comprar a Credicard, em processo da (dig) venda pelo Citibank. $\mathrm{O}$ banco havia oferecido cerca de $\mathrm{R} \$ 3$ bilhões para ficar pelo negócio (inc), mas não obteve resposta à proposta, cujo prazo expirou no final da semana passada. 0 anúncio oficial da desistência deve ser feito nesta segunda-feira.

Como parte de um projeto de extensão, um programa de alimentação saudável foi lançada (conc) nesta quarta por estudantes de Nutrição da USP. 0 projeto objetiva ensinar as pessoas a fazerem escolhas melhores e em porções do tamanho ideal. O programa foi apresentado na estação Sé do metro (acen), onde as pessoas podiam usar jogos em tablets para montar uma prato (conc) ideal, com a ajuda de nutricionistas.

De acordo com novo estudo, o encolhimento do cérebro na terceira idade pode ser contido por um enzima (conc). A pesquisa foi feita pela Universidade de Edimburgo, na Escócia, e analisou dados de 638 pessoas com 70 anos. Os resultado (conc) mostraram que a enzima, liberada durante a atividade física, diminui a retração do cerebro (acen) em até $30 \%$.

Meninos americanos podem estar entrando na puberdade mais cedo do que nas gerações anteriores, segundo pesquisa. Em comparação com dados de decadas (acen) atrás, meninos atendidos por pediatras entre 2005 e 2010 entraram na puberdade entre seis meses e dois anos mais tarde (inc). Os dados sugerem que, assim (dig) não são só as meninas que estão tendo seu desenvolvimento adiantado.

Após perder 10 quilos, a atriz Bárbara Paes nega que esteja com anorexia. Os boatos surgira (conc) depois que a atora (ort) postou fotos com o novo corpo no seu facebook. Ela não gostou dos comentários e desmentiu tudo ao vivo em um programa do SBT, no último domingo.

Bárbara disse que engordou (inc) fazendo dieta e aumentando os exercícios físicos.

No quadro "O que Vi da Vida", exibido no "Fantástico", a atriz Lilia Cabral falou sobre os problema (conc) de relacionamento que teve com o pai. Ela disse que o pai não aceitou quando ele (coer) deixou sua casa para trabalhar como atriz no Rio. A reconciliacão (ort) só ocorreu quando a mãe ficou doente, muito tempo depois.

Um teste rápido para identificar as causas da diarreia está sendo desenvolvido pela

Universidade de São Paulo. 0 exames (conc) identifica três tipos da principal bactéria causadora do problema. 0 método, que da (acen) resultado em 15 minutos, está em fase final de testes e deve estar disponivel (acen) no mercado em até dois anos.

\section{Quatro erros previstos}

A Organização Mundial do Comércio (OMP) (ort) elegeu hoje o novo diretor-geral da entidade. 0 escolhido é o embaichador (ort) brasileiro Roberto Carvalho de Azevêdo. 0 brasileiro disputou com a mexicano (conc) Herminio Blanco, de 62 anos, e assume o cargo em 32 (inc) de agosto.

Segundo o diretor de Administração e Finanças do Instituto Brasileira (conc) de Turismo, Tufi 
Neto, o Brasil receberá aproximadamente 600 mil turista (conc) durante a Copa do Mundo de 2015 (inc). Estima-se que a maioria serão (conc) da América Latina, pela proximidade geográfica. A última Copa, realizada em 2010 na África do Sul, atraiu ao país pouco mais de 300 mil turistas.

No Rio Grande do Sul, um esquema de liberação ilegal de licença ambientais (conc) foi denunciado por um funcionário público. A Polícia Federal iniciou as investigações e está intimando testemunhas para depor no inquérito. Mas (ort) de cem pessoas, além dos suspeitos presos, serão ouvidas no inquérito que investiga as irregularidade (conc), previstas para ser concluída (inc) até o final de maio.

Conforme divulgado pela Globo, a protagonista da próxima novela das 21 horas será (acen) interpretada por uma uma (dig) novata. A emisora (ort) divulgou que pretende investir em novos talentos. Na trama de Antônio Carlos, que vai estrear me (dig) março de 2013, a atriz fará o papel de uma empresária que perde tudo quando descobre que seu marido desviava dinheiro da empresa.

\section{Legenda:}

- Acen: acentuação

- Conc: Concordância - Inc: Incoerência

- An: Anáfora incorreta

- Dig: digitação - Ort: ortografia

- Sp: supressão de preposição 